\section{Health effects of tropical smoke}

Sir - Since August, large parts of Indonesia and Malaysia have been subjected to prolonged episodes of thick haze caused by smoke from intentionally set fires, chiefly in Sumatra and Borneo. As reported in Nature $^{1,2}$ and on many Internet web sites ${ }^{3}$, the haze has caused a serious health emergency for millions of people and many species of animals and has adversely affected agriculture.

A report ${ }^{4}$ on the incidence of upper respiratory tract infections (URTI) in Sarawak, Malaysia, shows that the average daily hospital and clinic visits from 5 to 28 August numbered 593 compared with the average for 1996 of 346 visits per day.

A more recent plot of hospital and clinic visits in Sarawak ${ }^{5}$ shows a very significant increase in URTI admissions in September, exceeding 3,000 on 23 September. The incidence of URTI was associated with an extraordinarily high air pollution index (API) which exceeded 900 on 23 September. An API greater than 400 is considered lifethreatening.

Although deforestation in Africa and South America has received considerably less notice than the Asian crisis, there was considerable smoke over substantial portions of these continents during the 1997 burning season. Satellite observations show half of Brazil was covered by smoke during parts of August and September.

The consensus of a meeting of physicians and health officials in Alta Floresta, Brazil, on 27 August, which was organized to hear results of my continuing UV-B, optical depth and airborne bacteria studies there, was that half the local population was suffering from respiratory disease. Dr Antonio Sinkos stated that he saw "two to three patients per week [with respiratory disease] before the burning and now eight a day".

He and his colleagues expressed particular concern about the effects of the smoke on asthmatics, children and the elderly. Health statistics for Alta Floresta are now being compared with measurements of optical depth and UV-B.

Studies of the health effects of severe air pollution in urban areas are complicated by multiple pollutant sources. The importance of the data from Sarawak and Alta Floresta is that they provide important information about the health effects of a single source of pollution, biomass burning. When combined with measurements of sharply diminished UV-B associated with thick smoke, these data also provide an important opportunity to study the increased incidence of disease caused by pathogenic bacteria and viruses which are ordinarily inactivated by solar ultraviolet ${ }^{6}$.

Although laws prohibit or regulate biomass burning in Indonesia and Brazil, enforcement is either lax or difficult. Until enforcement is achieved, there is a real possibility of smoke emergencies in future years. Countries at risk have a responsibility to prepare for future smoke emergencies, perhaps with the assistance of the international community and the UN Department of Humanitarian Affairs ${ }^{7}$.

Medical and scientific emergency response teams should be organized for immediate deployment to regions with serious smoke problems. Medical teams should be prepared to distribute suitable respirators (not merely dust masks), medical supplies and tracts that advise people why and how to avoid smoke. Scientific teams should be equipped with portable Sun photometers, radiometers and aerosol collectors. Observers in developing countries with limited budgets can assemble very inexpensive, accurate Sun photometers from readily available components ${ }^{8,9}$.

A few dozen scientists in Brazil, the United States and elsewhere have considerable experience of making smokerelated measurements and could participate in an international response to 
major smoke emergencies. All data should be freely shared among team members and scientists from the host countries.

The TOMS (Total Ozone Mapping Spectrometer) satellite instrument can reliably detect the presence of smoke over land ${ }^{10}$. Optical depth measurements of smoke in biomass burning regions can provide important calibration data for this instrument.

The close association of upper respiratory diseases with optical depth in Alta Floresta and the API in Sarawak suggest the possibility of using TOMS as an epidemiological tool to identify regions that might have smoke-related respiratory disease.

\section{Forrest M. Mims III}

Sun Photometer Atmospheric Network,

433 Twin Oak Road,

Seguin, Texas 78155 USA

e-mail:fmims@aol.com

1. Swinbanks, D. Nature 389, 321 (1997)

2. Nature 389, 315 (1997).

3. http://www.geocities.com/hotsprings/2188/haze.html (1997).

4. Environmental Health Unit, The haze in Sarawak, Epidem. News 7 (1997) available at http://ftp.http://ftp.sarawak.com.my/org/jkns/ haze97/haze1.htm.

5. http://ftp.sarawak.com.my/org/jkns/haze97/haze2.htm (1997).

6. Mims, F. M. et al. Science 276, 1774-1775 (1997).

7. UN Dept. of Humanitarian Affairs, http://www.reliefweb.int (1997).

8. Carlson, S. Sci. Amer. 276, 106-107 (1997).

9. Concord Consortium http://www.concord.org/haze/ (1997).

10. Herman, J.R. et al. J. Geophys. Res. 102, 16911-16922 (1997);

http://jwocky.gsfc.nasa.gov/.

\section{Progress on bioethics blocked in Japan}

Sir - Although I might agree with your opinion that "Japan's bioethics debate lags behind thinking in the West" (Nature 389, $661 ; 1997)$, it is misleading to say that "Japan's cultural and religious background" or a "lack of understanding" account for this state of affairs.

What is really blocking progress in bioethics-related issues in Japan is, first, the inability of the medical profession to govern itself and, second, deficiencies in Japan's approach to setting regulatory standards for research involving human subjects.

On the first point, any debate about bioethics is futile if medical practitioners and researchers are not subject to peer scrutiny and professional sanctions. In most countries, this is guaranteed by professional bodies with obligatory membership, similar to the General Medical Council in Britain or the German Ärztekammer. But there is no such organization in Japan.

The absence of a self-governing professional body and the subsequent lack of binding guidelines have created public distrust of the medical profession in Japan.
Although the Japan Obstetrics Society has issued guidelines to regulate reproductive technologies, these guidelines are regarded merely as 'opinions' and do not carry authority. This is the most noticeable difference between Japan and the West where bioethics is concerned.

On the second point, the principles governing human experimentation set out in the Nuremberg Code and the Declaration of Helsinki are generally regarded as the basis of contemporary medical ethics and bioethics, and national regulation should endorse these principles.

In Japan, only clinical trials of new drugs are subject to regulation based on these principles. Other medical procedures still at an experimental stage are often carried out as 'treatment' - not as clinical trials and are therefore not subject to appropriate regulation. This situation is more problematical even than individual technologies such as organ transplants.

The task in Japan is organizational and political and has nothing to do with alleged Japanese cultural uniqueness or persisting public misunderstandings.

\section{Jiro Nudeshima}

Life Science \& Society Programme,

Mitsubishi Kasei Institute of Life Sciences,

11 Minamiooya, Machida,

Tokyo, Japan 194

e-mail:jiron@libra.ls.m-kagaku.co.jp. 